\title{
Criminal compliance como medida de governança corporativa e seu papel na delimitação de responsabilidades penais*
}

\section{Criminal compliance as a measure of corporate governance and its function in the delimitation of criminal responsabilities}

\author{
Henrique Viana Pereira** \\ Renata Pereira Mayrink***
}

* Artigo recebido em 25 de maio de 2020 e aprovado em 9 de julho de 2020. DOI: http://dx.doi. org/10.12660/rda.v279.2020.82963.

** Pontifícia Universidade Católica de Minas Gerais, Belo Horizonte, MG, Brasil. E-mail: henriquepenal@gmail.com

Doutor e mestre em direito pela Pontifícia Universidade Católica de Minas Gerais (PUC-MG). Professor do Programa de Pós-graduação stricto sensu e da graduação em Direito da Pontifícia Universidade Católica de Minas Gerais (PUC-MG). Professor do Centro Universitário Unihorizontes. Advogado. Sócio do escritório Ariosvaldo Campos Pires Advogados.

*** Centro Universitário Estácio, Belo Horizonte, MG, Brasil. E-mail: renatapmayrink@gmail.com Mestre e doutoranda em direito pela Pontifícia Universidade Católica de Minas Gerais (PUC-MG). Bolsista CAPES. Pós-graduada em ciências penais pela Pontifícia Universidade Católica de Minas Gerais (PUC-MG). Professora do Centro Universitário Estácio de Belo Horizonte. Advogada. 


\section{RESUMO}

A inflação legislativa penal para controle dos riscos inerentes à atividade empresarial aumentou a importância da adoção de programas de cumprimentos nas pessoas jurídicas. O criminal compliance, como medida de governança corporativa, deve ser utilizado para evitar a ocorrência de crimes empresariais, bem como impedir os riscos de indevida responsabilidade criminal, auxiliando na individualização de condutas e identificação de agentes delitivos. Em que pese a necessidade de adaptação dos institutos do direito penal clássico ao novo contexto criminal empresarial e a dificuldade em se delimitar a autoria nos crimes cometidos no âmbito de corporações complexas, para correto combate a essa criminalidade se impõe a observância do método penal construído pela teoria do crime. Esse método, como objetivo geral, se revela verdadeira garantia individual diante do poder de punir do Estado. O método utilizado, essencialmente, foi o de revisão bibliográfica, com análise e interpretação da doutrina relacionada com o tema.

\section{PALAVRAS-CHAVE}

Sistemas de autorregulação - aspectos penais - criminal compliance governança corporativa - responsabilidade penal

\section{ABSTRACT}

Criminal legislative inflation to control the risks inherent to business activity has increase the importance of adopting compliance programs in legal entities. Criminal compliance, as a corporate governance measure, must be used to prevent the occurrence of corporate crimes, as well as to prevent the risks of undue criminal responsibility, helping to individualize conduct and identify criminal agents. In spite of the need to adapt the classic criminal law institutes to the new criminal business context, and the difficulty in delimiting authorship in crimes committed within the scope of complex corporations, for the correct fight against this criminality it is necessary to observe the constructed criminal method by the theory of crime. This method, as a general objective, proves to be a true individual guarantee in view of the State's power of punish. The method used, essentially, was bibliographic review, with analysis and interpretation of the doctrine related to the theme. 


\section{KEYWORDS}

Self-regulatory systems - criminal aspects - criminal compliance corporate governance - criminal responsibility

\section{Introdução}

Há constante instigação para reflexões sobre a responsabilização penal das pessoas físicas e jurídicas nos crimes cometidos no âmbito empresarial. A expansão da intervenção punitiva decorrente de uma inflação legislativa penal alavanca debates, não apenas sobre a possibilidade de imputação de pena aos autores de crimes praticados por meio do exercício de atividade empresarial, mas também sobre os benefícios e impactos na responsabilidade penal da adoção de medidas de governança coorporativa, entre as quais estão os programas de compliance.

Em decorrência das dificuldades enfrentadas pelo poder punitivo no combate à criminalidade econômica, cada vez mais o Estado demanda a participação dos agentes envolvidos na atividade empresarial para o enfrentamento dos delitos praticados em seu âmbito, aumentando a importância de sistemas de autorregulação. No âmbito penal, torna-se evidente a relevância dos compliance programs, conjunto de medidas tomadas pelas organizações que possui como finalidade precípua evitar a ocorrência de delitos em decorrência e por meio das atividades desenvolvidas, diminuindo os riscos de responsabilidade criminal, além de também auxiliar na individualização de condutas e identificação de agentes envolvidos na prática criminosa.

A complexidade das estruturas e atividades empresariais requer a prática da divisão de tarefas, havendo a assunção de funções por pessoas especializadas para desempenhá-las, e assumindo, esses agentes, o domínio direto sobre a realização da atividade e o controle sobre as fontes de perigo por ela geradas.

No exercício da atividade empresarial é comum que os administradores distribuam competências e confiem no regular cumprimento das atribuições delegadas, sendo transferíveis não apenas funções relacionadas com o objeto social da pessoa jurídica, mas também referentes à sua própria administração e controle. Nos programas de criminal compliance o chief compliance officer assume, por delegação, deveres, inerentes à gestão empresarial, de vigilância e controle, fiscalizando os focos de perigo gerados pela atividade, o que será feito por meio da implementação de mecanismos que evitem a subsunção de condutas a tipos penais previstos em lei. 
Recorrendo à transferência do poder-dever de evitação de crimes competidos no âmbito da corporação ao compliance officer, há a emergência de uma posição de garantia nova na pessoa jurídica, surgindo a indagação acerca da manutenção, ou não, da possibilidade de responsabilização dos órgãos diretivos. Nesse contexto é importante verificar se a delegação das funções, caso realizada de maneira adequada, é, de fato, capaz de exonerar os delegantes dos deveres de vigilância e controle direto sobre a atividade, ou se os órgãos de direção se desobrigam por completo da responsabilidade sobre o ofício delegado, mantendo uma posição de garantia residual que se baseia nos deveres de escolher corretamente aquele que irá assumir a incumbência, treinar o delegado corretamente para desempenho da função, fiscalizar suas atividades e garantir que terão as informações e meios materiais adequados para correta execução do encargo.

Em decorrência desses questionamentos se torna necessário analisar os aspectos penais dos sistemas de autorregulação, especificamente no que diz respeito ao criminal compliance como medida de governança corporativa. Pretende-se contribuir, destarte, para melhor entendimento dessas repercussões no contexto empresarial, com demonstração de estratégias regulatórias. É o que se passa a expor.

\section{O direito penal econômico e os programas de compliance}

O surgimento de normas que regulam todos os âmbitos de atuação social é uma característica do Estado moderno. Com o desenvolvimento econômico pós-industrialização e a expansão das fronteiras comerciais, houve o surgimento de perigos inéditos gerados primordialmente pela atividade econômica, e, portanto, proveio a necessidade da criação de mecanismos de controle, vigilância e regulamentação desse setor.

O direito econômico nasce a partir da exigência de intervenção do Estado na economia em meados do século $X X$, momento em que o governo passa a assumir a função de promover bem-estar social. Nesse contexto, de substituição de um Estado liberal pelo social intervencionista, e de apropriação pelo ente público da tarefa de promoção e realização da justiça social recorrendo à implementação de políticas, há o abandono da ideia de que esse objetivo seria alcançado naturalmente pelo mercado. Consequentemente, surgem normas jurídicas com a finalidade de orientar a atuação estatal e regulamentar as relações econômicas. 
Direito Econômico é o conjunto de normas de conteúdo econômico que, pelo princípio da economicidade, assegura a defesa e harmonia dos interesses individuais e coletivos definidos pela ideologia adotada na ordem jurídica e que regulamenta a atividade dos respectivos sujeitos na efetivação da política econômica posta em prática para concretização daquela ideologia. ${ }^{1}$

O surgimento do direito penal econômico está inserido no contexto de expansão moderna da tutela criminal e consequente enfraquecimento do caráter fragmentário do direito penal. A demanda por segurança, controle e transparência das atividades econômicas repercutiu não apenas na esfera cível ou administrativa, mas também no âmbito penal. Enquanto geradoras dos riscos sociais mais significativos aos interesses e bens da sociedade atualmente, as corporações empresariais se tornaram alvo da expansão normativa, em uma tentativa de mitigar os perigos gerados por essa atividade.

O direito penal econômico surge em um contexto de mudança de um direito penal repressivo, que atuava majoritariamente após a ocorrência do dano ao bem tutelado, para um preventivo e cujo bem jurídico é supraindividual, o que se deu pela necessidade de adequação dos paradigmas penais tradicionais a uma nova criminalidade, na qual se inclui a delinquência econômica. O direito penal tem aumentado consideravelmente seu campo de atuação, na tentativa de acompanhar o desenvolvimento social e as demandas por proteção, expandindo sua tutela para novas áreas, como a economia.

“Como parte integrante das transformações ocorridas, a partir da sociedade pós-industrial, surge a denominada criminalidade econômica, organizada, (...)".2 Ao incremento da criminalidade econômica, as instâncias de controle estatal reagiram editando uma série de leis de conteúdo penal econômico. ${ }^{3}$ A pesar da existência pretérita de normas de repressão às infrações

1 SOUZA, Washington Peluso Albino de. Primeiras linhas de direito econômico. Belo Horizonte: Rabelo \& Brasil Ltda, 1977. p. 1.

2 SEBASTIÃO FILHO, Jorge. A criminalização de condutas de perigo abstrato e a tutela de bens jurídicos supraindividuais nos delitos econômicos. Revista Jurídica, s.1., v. 25, n. 9, p. 33-57, dez. 2010, p. 49. Disponível em: <http://revista.unicuritiba.edu.br/index.php/RevJur/article/ view/58>. Acesso em: 11 set. 2019.

3 PALHARES, Cinthia Rodrigues Menescal. Aspectos político-criminais das sanções penais econômicas no direito brasileiro. In: SOUZA, Artur de Brito Gueiros (Org.). Inovações no direito penal econômico: contribuições criminológicas, político-criminais e dogmáticas. Brasília: Escola Superior do Ministério Público da União, 2011. seção II, p. 147. 
praticadas no âmbito das atividades econômicas, o direito penal econômico, pensado como um "(...) conjunto de normas relativamente homogêneas e destacadas do Direito Penal nuclear, somente surgiu no século XX". ${ }^{4}$

O conceito de direito penal econômico é objeto de controvérsia tendo em vista a diversidade de critérios que podem ser adotados para a definição. Utilizando o bem tutelado como referencial, o direito penal econômico pode ser conceituado como "el conjunto de normas jurídico-penales que protegen el orden económico". ${ }^{5} \mathrm{O}$ delito econômico abarca não somente a defesa penal da intervenção e regulação estatal na economia, mas também a tutela da sociedade contra transgressões no campo dos bens jurídicos supraindividuais e os delitos patrimoniais clássicos, esses quando atingem patrimônio coletivo ou constituem abuso de práticas comerciais. ${ }^{6}$

A despeito do destaque que tem sido dado ao direito penal econômico, defende-se, entretanto, que não há a criação de uma disciplina autônoma com a desvinculação em relação ao direito penal. Trata-se, em apertada síntese, de uma delimitação didática com a finalidade de permitir uma análise específica e aprofundada acerca da criminalidade econômica, que tem ensejado uma nova perspectiva de abordagem repressiva estatal que se adapte ao desenvolvimento econômico. Tendo em vista a mudança social pós-industrialização, é decorrência lógica que o direito penal tenha que acompanhar essa mudança de paradigma.

De fato, o Direito Penal Econômico tem se adaptado, com bastante frequência, às novidades que lhe são impostas. Em curtíssimo espaço de tempo, verificou-se mutação em diversos setores penais, desde novo tratamento supraindividual, novos institutos, traçando o que Nieto Martín qualifica, no âmbito penal econômico, como darwinismo jurídico, ou seja, uma significativa adaptação do Direito Penal Econômico através das mais diversas situações e modelos econômicos verificados ao longo dos anos. ${ }^{7}$

4 SOUZA, Artur de Brito Gueiros. Da criminologia à política-criminal: direito penal econômico e o novo direito penal. In: Artur de Brito Gueiros Souza, Inovações no direito penal econômico, op. cit., seção II, p. 105.

5 BAJO FERNÁNDEZ, Miguel; BACIGALUPO, Silvina. Derecho penal económico. Madri: Centro de Estudios Ramón Areces S.A., 2001. p. 11.

6 TIEDMANN, Klaus. El concepto de derecho económico, de derecho penal económico y de delito económico. Revista Chilena de Derecho, Santiago, v. 10, p. 59-68, 1983. p. 61. Disponível em: <https://dialnet.unirioja.es/descarga/articulo/2649428.pdf>. Acesso em: 25 set. 2019.

7 SILVEIRA, Renato de Mello Jorge; DINIZ, Eduardo Saad. Compliance, direito penal e lei anticorrupção. São Paulo: Saraiva, 2015. p. 66. 
O direito penal econômico se origina da necessidade de dar uma resposta mais severa, por intermédio da ameaça de pena, a comportamentos, muitas vezes já configuradores de ilícitos administrativos ou cíveis, quando atacam de forma grave os bens jurídicos supraindividuais mais importantes. No atual contexto, em que há um aumento de normas reguladoras da atividade econômica, principalmente no âmbito penal, surgem os programas de compliance, que fomentam a adequação da atividade empresarial às normas éticas e jurídicas e são essenciais para que se tenha algum controle sobre a complexa atividade corporativa. ${ }^{8}$

Este novo modelo de Direito Penal Econômico é caracterizado pela autorregulação regulada da economia pelo Estado, por meio da qual, a partir de previsões legais, fomenta ou impõe aos particulares um determinado modelo de organização, fiscalização e regulamentação dentro da pessoa jurídica capaz de prevenir crimes e, assim, diminuir os riscos relacionados à atividade econômica empresarial. Estas previsões legais de autorregulação regulada referidas à organização empresarial receberam o nome de Deveres de Compliance. ${ }^{9}$

Os compliance programs estão inseridos nos projetos de boa governança corporativa, que são práticas de gestão por meio das quais a organização empresarial é dirigida e monitorada visando preservar e otimizar seu valor econômico, além de sua longevidade, recorrendo aos controles preventivos e detectivos no gerenciamento dos riscos. Essa gestão, por intermédio dos programas de cumprimento, evita que ocorram violações ao direito e demais normas no desenvolvimento da atividade empresarial e, com isso, diminui as chances de que as pessoas jurídicas e seus administradores sejam responsabilizados por transgressões.

Nesse aspecto, a missão do compliance, segundo o Grupo de Trabalho da Associação Brasileira de Bancos Internacionais (Abbi) em conjunto com a Federação Brasileira de Bancos (Febraban), ${ }^{10}$ é certificar a adequação, o fortalecimento e o funcionamento dos mecanismos de controle internos da instituição, buscando mitigar os riscos de sanções legais ou regulatórias, perda

\footnotetext{
RODRIGUES, Anabela Miranda. Direito penal económico. Coimbra: Almedina, 2019. p. 57.

LUZ, Ilana Martins. Compliance e omissão imprópria. Belo Horizonte: D’Plácido, 2019. p. 19.

10 ABBI; FEBRABAN. Documento consultivo: função de compliance. 2004. p. 9. Disponível em: <www.abbi.com.br/funcaodecompliance.html>. Acesso em: 10 fev. 2020.
} 
financeira ou de reputação, de acordo com a complexidade dos negócios, bem como disseminar uma cultura de controles para assegurar o cumprimento de leis e regulamentos.

O desenvolvimento da cultura da boa governança corporativa e do compliance chegam em um momento em que passa a haver a necessidade e exigência de melhores ferramentas de controle da atividade empresarial. As corporações precisam estar em conformidade com leis e regulamentos externos e internos, semeando a obrigação individual de cada colaborador em atuar nesse sentido.

O progresso técnico e tecnológico das organizações empresariais não foi suficientemente acompanhado pelo Estado, que, diante de sua obsolescência, se tornou incapaz de regular completamente a atividade empresarial para controlar os riscos de sua atuação. Soma-se a esse panorama a insuficiência dos ordenamentos nacionais em disciplinarem atividades cada vez mais globalizadas. Diante das causas expostas e do poder hegemônico crescente das corporações, tem surgido um novo modelo de intervenção do Estado na economia denominado autorregulação regulada, que se baseia na cooperação entre poder público, entes regulados e outros atores sociais, como ONGs e sindicatos, com a finalidade de estabelecer perfis de comportamento e se encarregar de sua execução. Os programas de compliance se inserem nesses programas de self regulation. ${ }^{11}$

\subsection{Criminal compliance}

A expansão do direcionamento da tutela penal às atividades empresárias aumentou a possibilidade de responsabilizações normativas das corporações e de seus dirigentes, criando diversos deveres empresariais sob pena de sanção criminal. Aos riscos inerentes à empresa, que tradicionalmente estavam relacionados com a possibilidade de se competir com êxito no mercado, se somam hoje os riscos de responsabilizações jurídicas, que podem ter consequências por vezes mais graves que o risco econômico da atividade. ${ }^{12}$

11 NIETO, Adán. Responsabilidad social, gobierno corporativo y autorregulación: sus influencias en el derecho penal de la empresa. Política Criminal, Santiago, v. 3, n. 5, p. 1-118, jul. 2008. p. 4. Disponível em: <http://politcrim.com/wp-content/uploads/2019/04/A_3_5.pdf>. Acesso em: 29 nov. 2019.

12 BACIGALUPO, Enrique. Compliance y derecho penal. Cizur Menor: Arazandi, 2011. p. 21-22. 
Visando a preservação quanto a esse tipo crescente de acusação, surgem os mecanismos de compliance.

Numa síntese apertada, pode dizer-se que a criação de programas de compliance responde a dois aspectos fundamentais. Desde logo, à criação exponencial de normas legais reguladoras da atividade econômico-empresarial e à frequência das alterações legislativas, que, por sua vez, procuram acompanhar o ritmo vertiginoso a que hoje se processa a evolução ao domínio econômico. Para além disso, as empresas não querem ter problemas legais ou judiciais nos locais onde estão instaladas, devido aos custos aí implicados, desde logo reputacionais, e pretendem, por isso, que uma cultura corporativa adequada impregne toda a estrutura organizacional da empresa, tendo em vista a mitigação de riscos associados à sua atividade ${ }^{13}$.

Nesta perspectiva, a responsabilização jurídica que se pretende evitar decorre do descumprimento de regulações e leis que regem a atividade empresarial visando controlar os riscos por ela gerados. Essas responsabilidades são contidas por meio dos programas de cumprimento, ou programas de compliance, que também funcionam como uma forma de controle pelo Estado da atividade empresarial, domínio que tem se tornado cada vez mais difícil considerando a alta complexidade das organizações.

O controle da atividade da empresa e, assim, a prevenção, investigação, perseguição e repressão de condutas ilícitas, também da prática de crimes, por parte do Estado, estão, por isso, muito mais dificultados. Torna-se particularmente atrativa a transferência para as empresas destas competências que cabiam aos Estados e que estes agora terceirizam. Por seu turno, e dado o contexto de riscos exponenciais em que se desenvolvem sua atividade, as empresas estão interessadas em evitar o efeito boomerang dos riscos que produzem e, portanto, elas próprias interessadas em, desde logo, minimizarem a sua ocorrência. Emerge, pois, uma certa convergência no objetivo de as empresas procederam à regulação da sua atividade, que o Estado incentiva sem abrir totalmente mão dessa mesma regulação ${ }^{14}$.

13 Rodrigues, Direito penal económico, op. cit., p. 57.

14 Ibid., p. 49. 
No novo cenário social de aumento de riscos, em que se passou a exigir do direito penal uma nova forma de atuação, também foram criados deveres para os atores do setor econômico, ampliando-se a exigência de autorregulação empresarial também para a área criminal. Os programas de criminal compliance se constroem como uma forma de cooperação entre o ente privado e o poder público, e estão intrinsecamente ligados ao direito penal econômico, pois são um mecanismo que se esforça justamente para evitar a proliferação dos delitos econômicos, recorrendo ao aprimoramento dos controles internos da organização, além de também atuarem na facilitação da persecução desses crimes.

Nessa constatação em termos preventivos, onde o dano cede lugar ao perigo nas formulações típicas, percebe-se o alvorecer de uma nova tendência, inicialmente em sede do Direito Penal Econômico, mas não só, que vem a ser a assunção de preceitos éticos e de cumprimento normativo prévio por parte de empresas. Trata-se da chamada obediência a estamentos próprios, mormente autorregulatórios, tida, aqui, pela nomenclatura anglo-saxã compliance. Partindo-se de premissas éticas comportamentais prévias, novas lógicas de mercado parecem ter sido impostas ao Direito Penal, em um viés de criminal compliance. ${ }^{15}$

Voltando a atenção ao direito penal econômico, o criminal compliance vai além do simples cumprimento de normas e pode ser entendido como um mecanismo criado pela sociedade empresária que se presta à detecção e à prevenção de delitos decorrentes da atividade empresarial, possuindo como finalidade principal evitar a responsabilização criminal da corporação e seus administradores. ${ }^{16}$ Assim, o foco primordial da ferramenta não é apenas o cumprimento normativo, mas a mudança da cultura empresarial tradicional para minorar as chances de responsabilizações.

Trata-se o programa de compliance, portanto, da criação, implantação e fiscalização de normas de condutas e posturas internas da empresa,

15 Silveira e Diniz, Compliance, direito penal e lei anticorrupção, op. cit., p. 26.

16 SALLES, Leonardo Guimarães. Criminal compliance: a delimitação da responsabilidade penal nas organizações empresariais complexas. Dissertação (mestrado em direito) - Pontifícia Universidade Católica de Minas Gerais, Belo Horizonte, 2016. p. 98. Disponível em: <www. biblioteca.pucminas.br/teses/Direito_SallesLG_1.pdf>. Acesso em: 10 fev. 2020. 
com a finalidade de gerar consciência sobre deveres e obrigações na prevenção de riscos legais e regulatórios, possuindo também a função de distribuir responsabilidades entre os indivíduos que cooperam na sua administração. Pode ser voltado à prevenção dos riscos inerentes a diversas áreas de atuação da empresa, tais como: tributário, previdenciários, concorrencial, trabalhista, segurança do trabalho, ambiental, entre outras. Quando tais riscos tratam da possibilidade de responsabilização penal, fala-se em criminal compliance. ${ }^{17}$

Diante de uma ineficiência do Estado moderno em lidar com os novos perigos a que está exposta a sociedade, e visando as corporações minimizar os riscos de punição por condutas sancionáveis em um sistema normativo cada vez mais melindroso e instável, ganham gradativamente mais importância os sistemas de autorregulação, como o compliance, que se inserem entre as possíveis medidas de governança corporativa que podem ser adotadas pelas sociedades empresárias.

A temática sobre a imputação de responsabilidade penal na prática de crimes econômicos possui um ponto crítico, que é a atribuição de responsabilidade às pessoas que fazem parte das corporações quando o delito é cometido no exercício da atividade empresarial.

O atual cenário em que a atividade econômica se desenvolve é altamente complexo, e a organização empresarial por vezes dificulta a identificação dos responsáveis pelo delito. Nesse contexto, o criminal compliance se mostra, também, como um importante instrumento de redução dessas complexidades existentes, já que, aumentando o controle sobre condutas no exercício da empresa, individualiza as ações e possibilita o reconhecimento do delito e seus autores, impacta, ainda, na responsabilização da direção empresarial ou dos responsáveis pelo cumprimento, como garantidores a respeito dos delitos cometidos por seus subordinados.

\footnotetext{
SARCEDO, Leandro. Compliance e responsabilidade penal da pessoa jurídica: construção de um novo modelo de imputação, baseado na culpabilidade corporativa. 2014. Tese (doutorado em direito) - Faculdade de Direito, Universidade de São Paulo. São Paulo, 2014. p. 56. Disponível em: <www.teses.usp.br/teses/disponiveis/2/2136/tde-07122015-163555/pt-br.php>. Acesso em: 25 set. 2019.
} 


\section{Criminal compliance e a dificuldade no enfrentamento de delitos econômicos}

Entre as questões que inquietam o direito penal econômico, pode-se citar não apenas a especificidade do bem jurídico tutelado e a necessidade de se antecipar às lesões aos valores fundamentais, mas também a peculiaridade sobre os sujeitos ativos da delinquência econômica e seu modus operandi. A criminalidade que ocorre dentro das pessoas jurídicas revela uma dificuldade acerca da verificação correta da autoria, e, até mesmo, uma complicação para apurar a materialidade do fato criminoso, destacando a importância do criminal compliance, visto como uma maneira de redução da obscuridade verificada na atividade empresarial. Diante das estruturas corporativas, caracterizadas pela descentralização das decisões, além da diferenciação de funções e tarefas, tornou-se extremamente árdua a individualização da responsabilidade penal.

Em uma primeira análise acerca da importância dos programas de cumprimento na criminalidade empresarial, o enfoque é a responsabilidade penal das pessoas coletivas. Trata-se da possibilidade de uma sociedade empresária ser responsabilizada por crimes que seus funcionários pratiquem no exercício da atividade, em virtude da falta de organização conforme lhe era devido. As corporações têm o dever de prevenir adequadamente a ocorrência de crimes em seu favor, e, nesse ponto, a existência de um programa efetivo de compliance é determinante para o afastamento da imputação, pois certifica que houve o cumprimento do dever legal de diligenciar para garantir que seus membros não pratiquem crimes.

Ademais, a criação dos programas de compliance se mostra útil para as sociedades empresárias que, desejando evitar custos com problemas judiciais e manter uma boa reputação e valor no mercado, preferem observar e disseminar uma cultura interna de cumprimento. ${ }^{18}$ Diante do contexto de ampliação normativa em direção à atividade empresarial, os programas de autorregulação aparecem para pessoas jurídicas carregando uma nova mensagem, de que uma correta organização interna com o fim de prevenir e detectar fatos delituosos pode lhes exonerar das sanções ou para que essas sejam diminuídas. ${ }^{19}$

18 Rodrigues, Direito penal económico, op. cit., p. 57.

19 MARTín, Adán Nieto. Problemas fundamentales del cumplimiento normativo en el derecho penal. In: LOTHAR, Kuhlen; MONTIEL, Juan Pablo; GIMENO, Iñigo Ortiz de Urbina (Ed.). Compliance y teoría del derecho penal. Madri: Marcial Pons, 2013. p. 26. 
Uma vez afastada a responsabilidade penal do ente coletivo que configura a organização empresarial, a questão passa a ser a responsabilidade penal dos administradores, e eventuais delegados, pelo descumprimento do dever que lhes incumbe de prevenção de ilícitos penais. Não há dificuldade em se imputar o crime àquele que age diretamente, no interesse ou em benefício da pessoa jurídica, isso porque, nesses casos, há clareza quanto ao executor da infração penal. Entretanto, nas grandes corporações e sociedades empresárias há uma atomização de condutas e até mesmo das decisões que possam levar à configuração dos delitos, o que faz com que diversas ações e omissões concorram para a ocorrência do resultado delitivo tornando difícil a afirmação de responsabilidades penais com base na imputação individual.

Se a dogmática tradicional se revela insuficiente para resolver o problema das atividades empresariais organizadas de forma complexa, tal acontece por ainda não ter sido tratada de forma satisfatória uma característica central das sociedades modernas, como o é a organização empresarial com a consequente repartição de funções e tarefas dentro da organização. Neste domínio de criminalidade já não encontramos um autor que toma a decisão de realizar um fato típico, com conhecimento do alcance de sua decisão, e que executa essa decisão. Muito pelo contrário. Nas grandes empresas e sociedades potencialmente perigosas para bens jurídicos fundamentais assiste-se uma atomização ou fragmentação de movimentos corpóreos, decisões de política geral, conhecimento sobre riscos e recolha de informações pelas empresas sobre o seu impacto no ambiente circundante, de tal modo que a partir de um certo grau de complexidade já não é mais possível encontrar uma pessoa na qual coincidam criação ou participação no risco, com representação desse mesmo risco, ou que disponha de informação global sobre a atividade empresarial. Os gerentes e administradores têm uma visão demasiado global e aqueles que conhecem diretamente os efeitos da atividade empresarial não têm a visão de conjunto necessária para compreender a perigosidade que encerram certas atividades industriais ou empresariais. Na grande empresa não concorrem nas mesmas pessoas informações e conhecimentos técnicos e a capacidade para tomar e executar decisões. ${ }^{20}$

20 FEIJÓO SÁNCHEZ, Bernardo José. Autoria e participação em organizações empresariais complexas. Tradução de Vânia Costa Ramos. Revista Liberdades, São Paulo, n. 9, p. 26-57, 
A imputação penal está tradicionalmente assentada na responsabilidade individual, que tem como referência um agente autorresponsável, que executa diretamente a conduta típica, e que dispõe das informações necessárias sobre as circunstâncias elementares do tipo e riscos criados por seu comportamento. ${ }^{21}$ Ademais, esse sujeito tem a capacidade de compreender o caráter ilícito do fato e, ainda assim, opta por agir de forma contrária ao direito. Ocorre que a prática de crimes no exercício da empresa gera desafios para todos os pressupostos da responsabilidade penal individual, o que se deve ao fato de serem sociedades cuja estrutura é complexa, e o modo utilizado para desenvolvimento da atividade consiste em uma compartimentação de funções, tarefas e informações.

As técnicas de organização da empresa - divisão de funções e divisão de trabalho, com a correlata fragmentação da informação - também desempenham um papel relevante, pois implicam, muitas vezes, em que o resultado delitivo somente seja reconduzível a um aglomerado de ações e omissões, as quais, isoladamente, pouco representam em termos de reunião dos elementos que permitiriam ao agente compreender o caráter injusto de seu comportamento. Some-se a isso que a essa fragmentação objetiva na prática do injusto corresponde uma fragmentação subjetiva, ou seja, o agente pode contribuir objetivamente para a prática do injusto, desconhecendo as contribuições dos demais e, assim, não tendo como compreender o significado criminoso de sua contribuição. Esses dois aspectos da fragmentação das atividades dentro da empresa, o objetivo e o subjetivo, podem levar à redução da compreensão quanto ao significado criminoso do aporte individual, afetando o aspecto subjetivo, e produzindo uma aparente "indiferença" do colaborador. ${ }^{22}$

A secessão do trabalho característica da atividade empresarial implica que o resultado delituoso eventualmente existente possa ser imputado a várias

jan./abr. 2012. p. 27-28. Disponível em: <http://201.23.85.222/biblioteca/index.asp?codigo_ sophia=91297>. Acesso em: 23 fev. 2020.

21 ESTELITTA, Heloisa. Responsabilidade penal dos dirigentes de empresas por omissão: estudo sobre a responsabilidade omissiva imprópria de dirigentes de sociedades anônimas, limitadas e encarregados de cumprimento por crimes praticados por membros da empresa. São Paulo: Marcial Pons, 2017. p. 37-38.

22 Ibid., p. 40-41. 
condutas individuais. Tradicionalmente, quando há essa multiplicidade de condutas contribuindo para um mesmo crime, configura-se o concurso de pessoas. Mas, para que se configure o concurso de pessoas, é necessário identificar a reunião de quatro requisitos cumulativos: pluralidade de pessoas e de condutas, comissivas ou omissivas, liame subjetivo entre os agentes, nexo causal entre as condutas e identidade de infração penal, e o que se percebe é que, diante da complexidade de uma criminalidade empresarial, não é fácil comprovar a presença de todos esses requisitos, especialmente a relação de causalidade dos comportamentos dos agentes envolvidos em relação ao resultado ilícito e ao vínculo psicológico que une aqueles que colaboraram para o delito.

Como o nexo causal funciona como um elo que permite a atribuição de um resultado a todos os agentes envolvidos na prática criminosa, essa conexão se torna obscura quando as contribuições são indiretas e estão inseridas em uma cadeia de divisão de competências, decisões e tarefas. Ademais, a repartição do trabalho na empresa dificulta o enquadramento como coautores ou partícipes de um mesmo crime, haja vista que não há um plano em comum entre os agentes, liame subjetivo, cujas contribuições são autônomas, e, muitas vezes, sequer existe uma comunicação estabelecida. ${ }^{23}$

A divisão funcional da empresa, tanto do ponto de vista vertical quanto do ponto de vista horizontal, hierárquico, apresenta entraves para o sistema de imputação penal de responsabilidades, pois a execução material do crime, a posse de informações relevantes, a capacidade de decisão e as condições subjetivas de autoria podem estar presentes em sujeitos distintos dentro da mesma organização. $\mathrm{O}$ controle sobre o acontecer típico é dificultado pelo modo em que é praticada a atividade empresarial, o que pode levar tanto a uma ampliação desarrazoada do número de agentes que serão responsabilizados pelo delito quanto à impossibilidade de imputação penal a qualquer sujeito envolvido, no que se denomina "irresponsabilidade organizada" ${ }^{24}$

De qualquer modo, o que se tem observado é a ampliação das estruturas dos institutos criminais, para que o sistema penal seja capaz de satisfazer às expectativas sociais de punição severa dos agentes envolvidos na concretização dos riscos modernos advindos da atividade econômica. Em decorrência desse

23 Ibid. p. 43.

24 SILVA SÁNCHEZ, Jesús-María. Teoría del delito y derecho penal económico. Revista Brasileira de Ciências Criminais, São Paulo, v. 20, n. 99, p. 327-356, nov./dez. 2012. p. 329. Disponível em: <http://201.23.85.222/biblioteca/index.asp?codigo_sophia=98496>. Acesso em: 27 nov. 2019. 
contexto, surge a responsabilização da própria pessoa jurídica, enquanto ente coletivo, bem como a imputação da responsabilidade penal aos dirigentes da corporação.

Não obstante, apesar das dificuldades existentes para a imputação penal individual no âmbito da criminalidade empresarial, não é aceitável que se cogite uma responsabilidade presumida, a título de omissão imprópria, de determinados sujeitos pela mera ocupação de uma posição na estrutura empresarial. O primeiro pressuposto para imputação comissiva por omissão é, de fato, a existência da posição de garantidor, mas essa função não basta, devendo somar-se ainda à análise dos demais elementos do crime.

Ao reconhecer os obstáculos encontrados pela teoria do delito no âmbito do direito penal econômico, Silva Sánchez conclui que "el modelo clásico del delito doloso de acción, asentado sobre las nociones tendencialmente empíricas de causalidad, dominio e intención, se halla superado", ${ }^{25}$ tendo sido substituído pela omissão e dolo eventual nos contextos das atividades de risco, aumentando-se a relevância dos elementos de infrações de dever na teoria do delito. Assim, essa mudança paradigmática ocasionaria, no plano objetivo, uma diminuição da importância da causalidade física, entre a conduta do sujeito e resultado, já no plano subjetivo, uma tendência à relativização na análise dos elementos subjetivos da conduta. ${ }^{26}$

\subsection{Imputação da responsabilidade penal aos dirigentes de corporações empresariais}

A conduta típica pode se realizar por ação ou por omissão. Se a conduta comissiva é aquela que exige do sujeito um movimento corporal violador de uma norma proibitiva, a conduta omissiva pura consiste em um não fazer diante de uma exigência legal de ação esperada. Determinados crimes comissivos, no entanto, podem ter seus resultados alcançados também por omissão; nesses casos, quando se viola uma norma proibitiva por omissão, o crime é chamado de omissivo impróprio, ou comissivo por omissão. ${ }^{27}$

Esses delitos consistem em uma omissão que se equipara à conduta comissiva quando o agente devia e podia agir para impedir o resultado, de

25 Ibid., p. 330.

26 Ibid. p. 331.

27 BRANDÃO, Cláudio. Teoria jurídica do crime. 5. ed. Belo Horizonte: D’Plácido, 2019. p. 88. 
modo que os titulares do dever podem responder penalmente pelo resultado típico como se o houvessem causado ativamente, desde que comprovados outros requisitos da teoria do crime. O art. 13, § 2, do Código Penal emparelha a omissão à conduta comissiva quando há uma posição de garantidor do agente, descrita no dispositivo como um dever de agir e, em suas alíneas, o diploma, então, expõe aqueles que possuem o dever especial de atuação para evitar a consequência lesiva, os garantidores. Assim, a imputação penal a título de omissão imprópria depende, em primeiro lugar, do reconhecimento da condição garantidora do indivíduo, segundo as hipóteses legais.

Legalmente, o dever de agir desses agentes está previsto no art. 13, $\S 2 \stackrel{\circ}{\circ}$, do Código Penal, que adota, em primeiro momento, como fundamento a teoria dos deveres formais, incumbindo o dever de agir àqueles que tenham por lei a obrigação de cuidado, proteção ou vigilância, ou àqueles que assumiram a responsabilidade de impedir o resultado por outra forma. A concepção legal determina que a obrigação de evitar o resultado se funda em imposição contida em norma extrapenal, o que significa dizer que todos os indivíduos que possuem formalmente um dever extrapenal de salvamento ou vigilância poderiam ser considerados garantes para fins penais. ${ }^{28}$ À teoria destacada, posteriormente, foi incluída a ingerência, ou seja, passou-se a admitir para configuração do dever de garantia, além da previsão formal extrapenal, também a hipótese da criação anterior de uma situação de perigo para o bem tutelado. ${ }^{29}$

O desenvolvimento da empresa gera inúmeros e relevantes reflexos na comunidade, já que a atividade concentra a prestação de serviços, fornecimento de bens, geração de empregos, arrecadação fiscal e contribui para a interligação da economia de mercado. Nesse diapasão, essa atividade deve ser tratada não apenas como uma produtora de riquezas, mas também como um poder. $\mathrm{O}$ exercício desse poder implica obrigações a serem cumpridas. A autonomia que se concede para o desempenho da atividade em um contexto liberal possui uma contrapartida, que é o cumprimento pela pessoa jurídica de sua função social. “Os atos empresariais não devem apenas evitar fins antissociais, mas, além disso, devem estar em conformidade com a razão pela qual a livre-iniciativa foi garantida e reconhecida: busca da dignidade e da justiça social." 30

28 Estelitta, Responsabilidade penal dos dirigentes de empresas por omissão, op. cit., p. 81.

29 Luz, Compliance e omissão imprópria, op. cit., p. 205.

30 PEREIRA, Henrique Viana. A função social da empresa e as repercussões sobre a responsabilidade civil e penal dos empresários. Tese (doutorado em direito) - Pontifícia Universidade Católica 
Então, a empresa deixa de ser vista como um instrumento de satisfação egoística dos sócios e administradores da sociedade empresária, e passa a ser analisada dentro de um contexto social, eis que, sob o contexto de um Estado Democrático de Direito, as atividades devem ser voltadas para a realização de valores como a liberdade e dignidade e, por isso, não se permite que autonomia se confunda com alvedrio. ${ }^{31}$

O risco da atividade empresarial, no contexto das pessoas jurídicas, é assumido primeiramente pela própria pessoa jurídica, titular dos direitos e deveres inerentes ao exercício da atividade econômica. Contudo, ainda que se reconheça alguma capacidade de assunção de responsabilidades penais, a sociedade empresária depende de humanos para atuar, de modo que, ao final, a essas pessoas físicas recaem os deveres de vigilância sobre as atividades empresariais essencialmente perigosas e os encargos advindos da organização e gestão empresarial, como verdadeiros garantes primários. ${ }^{32}$

Pode-se apontar duas espécies de omissões equiparáveis às ações, havendo dois tipos de garantes, aqueles cuja função surge ante um dever de proteção ou diante de um dever de vigilância sobre a fonte de perigo. No primeiro caso, os garantidores devem proteger um bem jurídico contra todo e qualquer perigo que o ameace, independentemente de sua fonte causadora. Já no segundo caso, cabe ao garantidor, em virtude da responsabilidade por uma fonte de perigo, assegurar que essa causa se mantenha dentro dos limites legais.

La posición de garante consiste, pues, en una posición de protección con respecto a un bien jurídico. La tarea de defensa del garante puede orientarse en dos direcciones: por una parte, el sujeto del mandato puede tener que estar "vigilante" para proteger determinado bien jurídico contra todos los ataques, vengan de donde vengan; aquí la función de protección consiste en la "defensa en todos los flancos" del concreto bien jurídico contra peligros de todo género. (...) Por otra parte la posición de garante puede consistir en la supervisión de determinada fuente de peligros, no importando a qué bienes jurídicos amenazan peligros desde esta fuente, La misión de protección del

de Minas Gerais, Belo Horizonte, 2014. p. 146. Disponível em: <www.biblioteca.pucminas.br/ teses/Direito_PereiraHVd_1.pdf $>$. Acesso em: 21 fev. 2020.

31 Ibid., p. 147.

32 Estelitta, Responsabilidade penal dos dirigentes de empresas por omissão, op. cit., p. 131. 
garante tiene por contenido el "poner coto a la concreta fuente de peligros"; solo secundariamente, como efecto reflejo, se deriva la garantía de aquellos bienes jurídicos amenazados por esta fuente de peligros. ${ }^{33}$

Os empresários e diretores das pessoas jurídicas, por criarem a fonte de perigo a bens jurídicos de terceiros atuando dentro de sua esfera de autonomia, e tendo domínio direto sobre essa fonte, se vinculam ao dever de agir para que essa se mantenha em padrões aceitáveis. É a criação do foco de riscos que legitima o dever de agir imposto a esses agentes, fundamento previsto na alínea $c$ do art. $13, \S 2 \stackrel{\circ}{ }$, do Código Penal. Esse dispositivo prevê que aquele que cria o risco da ocorrência do resultado com um comportamento anterior tem o dever de agir para evitar consequências indesejadas. Caso não o faça, sua omissão será penalmente relevante. Assim, os empresários e diretores das pessoas jurídicas se vinculam a esses deveres especiais de conduta, cujo não exercício os faz responsáveis a título de omissão imprópria. ${ }^{34}$

A ideia básica que fundamenta a posição de garantia dos órgãos de direção da empresa reside em que com o estabelecimento da organização o empresário assume o compromisso de conter aqueles riscos que venham a surgir da empresa para os bens jurídicos dos demais. Esta é a contrapartida da liberdade exercida mediante o estabelecimento da empresa. Resulta pacífico que a responsabilidade em comissão por omissão poderá ser fundamentada quando a empresa converte-se em um foco evidente de perigos. ${ }^{35}$

Nesse diapasão, são garantidores originários e possuem, portanto, o dever de vigilância primário, "aquelas pessoas que tenham uma relação juridicamente fundada de controle sobre a fonte de perigo da empresa, que tem que ser confirmada pela assunção fática dessas tarefas" 36 , ou seja, incumbe aos empresários e membros dos órgãos diretivos da corporação,

33 KAUFMANN, Armin. Dogmática de los delitos de omisión. Tradução de Joaquín Cuello Contreras e José Luis Serrano González de Murillo. Madri: Marcial Pons, 2006. p. 289-290.

34 REBOUÇAS, Sérgio Bruno Araújo. Omissão imprópria do empresário: o problema da delegação dos deveres de garantia nas estruturas empresariais complexas. Revista Brasileira de Ciências Criminais, São Paulo, v. 26, n. 143, p. 45-86, maio 2018. p. 47. Disponível em: <http://201.23.85.222/biblioteca/index.asp?codigo_sophia=143403>. Acesso em: 23 out. 2019.

35 Planas, Estudos de dogmática jurídico-penal, op. cit., p. 249.

36 Estelitta, Responsabilidade penal dos dirigentes de empresas por omissão, op. cit., p. 132. 
que são os criadores e responsáveis pela gestão da atividade empresarial, o dever de vigilância e a posição primitiva de garantia. Pode-se afirmar que os empresários, nesse contexto, seriam garantes de vigilância, com dever de proteção:

Al plantearnos aplicar esta división sistemática de las funciones del garante en el ámbito de las relaciones empresariales, surge la cuestión de que ambos tipos pueden ser asumidas por un mismo garante, en función de cómo sean interpretadas las labores de protección y vigilancia. Un empresario - como veremos - será el garante de impedir que su actividad empresarial afecte a bienes jurídicos concretos, pero en el modo de llevar a cabo esa obligación se confunden las posiciones de garante de protección y vigilancia. Por ejemplo, un empresario de una compañía de transporte de autobuses debe asegurarse que sus vehículos están en perfecto estado de seguridad para proteger la vida y la integridad de sus clientes, lo que le convertiría en un garante de protección, pero el modo de proteger ese bien jurídico es precisamente vigilar las fuentes de peligro, que son el estado de seguridad de los autobuses y la formación del conductor. ${ }^{37}$

A responsabilidade omissiva imprópria dos componentes dos órgãos diretivos, entretanto, deve ser delimitada, e se restringe aos atos praticados pelos funcionários em benefício da associação. A posição de garantidor dos dirigentes está fundada no risco gerado pela atividade, e, portanto, a responsabilidade penal deve estar a ela atrelada. As condutas cometidas por colaboradores, segundo interesses próprios ou de terceiros estranhos à pessoa jurídica, não podem ser evitadas recorrendo a medidas de prevenção corporativas, sendo, nesses casos, os empregados sujeitos autorresponsáveis que respondem pessoalmente.

Vale esclarecer que, apesar da possibilidade de a relevância causal da omissão ser dolosa ou culposa, um ato derivado de uma conduta omissiva negligente não pode ser imputado a título de dolo. A análise do elemento subjetivo não permite responsabilização penal nesse caso.

A ninguém pode ser imputado um dever geral de impedir delitos ou atos ilegais praticados por outrem, responsabilizando-o por omissão porque não

37 LAFUENTE, Alfredo Liñán. La responsabilidad penal del compliance officer. Cizur Menor: Thomson Reuters Aranzadi, 2019. p. 42. 
impediu qualquer ação de terceiro. Isso apenas é possível quando o sujeito, além de se encontrar na posição de garantidor, tenha o autor do fato a ele vinculado, a ele subordinado, ou esse autor lese bens jurídicos de quem esteja sob os seus cuidados diretos. ${ }^{38}$

Se o fundamento da posição de garantidor dos dirigentes é seu controle sobre a fonte de perigo empresa, apenas os crimes que sejam decorrentes dos processos e atividades próprios dessa fonte de perigo é que podem ser submetidos aos deveres de vigilância dos dirigentes e, pois, em caso de omissão de agir para evitá-los, serem imputados aos dirigentes. ${ }^{39}$

Diante da complexidade da atividade empresarial, é habitual que nas grandes corporações exista uma fragmentação das diversas funções e atividades desenvolvidas. Essa setorização, que pode ocorrer sob um ponto de vista horizontal, por exemplo, quando há divisão em diretorias especializadas, ou entre níveis hierárquicos distintos mediante delegação, pode envolver não apenas as atividades que constituam objetivo social da sociedade, mas também funções ligadas à administração e controle sobre as atividades de perigo, o que fundamenta o surgimento de novas posições de garantia nos agentes delegados.

A relações interpessoais, geralmente, são regidas pelo princípio da separação das esferas, em que os sujeitos são autorresponsáveis pelas suas condutas e resultados alcançados. Entretanto, em algumas hipóteses se estipulam a determinados indivíduos deveres especiais de neutralização de riscos ou evitação de resultados que são produzidos em esferas de organização alheias. Existindo fundamentação normativa da posição de garantia, estabelece-se o dever de vigilância sobre esferas de outrem, como ocorre na relação entre direção empresarial e demais diretores e empregados. Uma vez escolhidos corretamente os funcionários da corporação, a relação explicitada seria então regida pelo princípio da confiança, em que os membros da alta cúpula empresarial poderiam confiar que os subordinados irão atuar corretamente.

Não obstante, levando-se em consideração a potencialidade criminógena da atividade corporativa que configura um foco de risco especial, seria possível duvidar da retidão da conduta dos funcionários, implicando a necessidade de

38 TAVARES, Juarez. Fundamentos de teoria do delito. Florianópolis: Empório do Direito, 2018. p. 406.

39 Estelitta, Responsabilidade penal dos dirigentes de empresas por omissão, op. cit., p. 137. 
se estabelecer controles orientados à neutralização desses riscos. ${ }^{40}$ A relação entre direção empresarial e subordinados então passaria a ser regida não mais pela confiança, e sim pela desconfiança que gera um dever de vigilância.

En conclusión, el deber de vigilancia del superior sobre la conducta de un subordinado, derivado de la existencia de una relación de desconfianza con respecto a este, comprendería dos deberes: un deber previo de obtención de conocimiento acerca del modo en que el subordinado gestiona su esfera de competencia; y un deber posterior de instar a este a la corrección de tal actuación defectuosa en el seno de su esfera de competencia, evitando las consecuencias lesivas derivadas de aquella. ${ }^{41}$

Não se exige que exista uma revisão completa de todas as condutas dos subordinados, o dever de vigilância pode ser cumprido com inspeções periódicas, criação de mecanismos de reportes obrigatórios, ou mesmo pela criação de órgãos específicos incumbidos dessa tarefa, como o compliance office. Havendo um desses mecanismos, a relação passa novamente a ser regida pelo princípio da confiança, já que os administradores poderão novamente crer que da atividade empresarial não resultarão corolários lesivos, tendo em vista a vigilância exercida pelo setor de cumprimento.

Concebendo-se o programa de criminal compliance como uma estrutura criada na organização com a finalidade precípua de prevenir a ocorrência de delitos, o compliance officer, profissional responsável por estabelecer, fazer cumprir e fiscalizar o projeto, recebe por delegação os deveres de vigilância e controle da atividade empresarial no que tange à observância da legalidade. Então, os deveres próprios da direção da organização são delegados ao compliance officer, quem, entre outras coisas, assume a guarda do correto cumprimento do direito pelos colaboradores da pessoa jurídica. ${ }^{42}$

A função compliance assume o dever de criar e assegurar o cumprimento de regulamentos internos à pessoa jurídica, implementar procedimentos de controle das atividades desenvolvidas, instituir sistemas de informações e assegurar sua funcionalidade, fomentar a cultura de conformidade e,

40 SILVA SÁNCHEZ, Jesús-Maria. Deberes de vigilância y compliance empresarial. In: Lothar, Montiel e Gimeno, Compliance y teoría del derecho penal, op. cit., p. 87.

${ }^{41}$ Ibid., p. 88 ,

42 Planas, Estudos de dogmática jurídico-penal, op. cit., p. 252. 
principalmente, assegurar a aderência e cumprimento das leis e princípios éticos pelos colaboradores.

A despeito do exposto, a gestão da empresa, uma vez delegadas às funções ao compliance officer, não se desincumbe completamente da posição de garante, a qual apenas se modifica. Inicialmente responsáveis por evitar os cursos lesivos que surgem da atividade empresarial, os diretores transferem essa incumbência ao chief encarregado do programa de cumprimento, todavia lhes surge o dever de fiscalizar o correto desenvolvimento da atividade por parte do delegado e de promover as condições para o bom desempenho de suas funções.

(...) debe entenderse que la delegación de competencias constituye un mecanismo de transferencia y transformación de posiciones de garantía. Transferencia porque, em virtud de la delegación, el garante hace surgir una posición de garantía en el delegado. Transformación, porque la posición de garantía del delegante no desaparece, sino que se transforma. En virtud de dicha transformación, la posición de garantía del delegante pasa a verse como secundaria o residual. Al delegante ya no le compete el deber de control directo de los focos de riesgo que se hallan en el ámbito de competencia del delegado. Pero sí le incumben una serie de deberes con objeto diverso: la correcta selección, formación - sifuera precisa - einformación del delegado; la dotación a este con los medios necesarios para el cumplimiento de sus funciones; la coordinación de la actuación de los diversos delegados; y sobre todo - al menos, eso es lo que suele indicarse - el deber de vigilancia. ${ }^{43}$

Conforme Heloísa Estellita, ${ }^{44}$ uma vez que ocorre a delegação, o superior hierárquico só pode confiar em seu subordinado caso o tenha escolhido adequadamente segundo as habilidades necessárias, se o houver instruído para o exercício da função e tenha lhe dado condições concretas para o desempenho de suas tarefas. Ainda assim, contudo, permanecem os diretores incumbidos de supervisionar o desempenho da função pelo compliance officer.

Como forma de impedir uma responsabilização irrestrita dos membros dos órgãos diretivos e profissionais de compliance, surge a preocupação com a determinação e a delimitação dos pressupostos da responsabilidade penal

43 Silva Sánchez, Deberes de vigilância y compliance empresarial, op. cit., p. 81.

44 Estelitta, Responsabilidade penal dos dirigentes de empresas por omissão, op. cit., p. 153. 
dos indivíduos que ocupam referido cargo. A análise da punibilidade desses indivíduos não deve ser feita a partir de uma perspectiva meramente formal da posição de garante. A propósito, a afirmação da função de garantia é apenas o passo inicial do caminho a ser percorrido, que perpassa pela análise de todos os elementos do crime.

\section{Conclusão}

Assiste-se a uma mudança de paradigma do direito penal tradicional em virtude de um contexto histórico singular no qual a sociedade hodierna, que convive com um intenso desenvolvimento tecnológico, científico e econômico, experimenta o surgimento de novos riscos como uma consequência indesejada do processo de modernização, riscos esses advindos principalmente da atividade empresarial.

Para se anteciparem a um direito penal essencialmente preventivo, as pessoas jurídicas têm adotado programas de cumprimento. Os compliance programs criminais são importante instrumento utilizado pelas sociedades empresárias para prevenção de delitos por meio da programação de condutas que diminuem os riscos causados pela atividade. Trata-se do desenvolvimento de políticas, normas e meios de fiscalização internos com a finalidade de evitar a subsunção de condutas praticadas no contexto da atividade empresarial a tipos penais previstos em lei.

O criminal compliance como medida de governança corporativa é útil, em um primeiro momento, para afastar a imputação de crimes à própria pessoa jurídica. Já em um segundo momento, volta-se para facilitar a individualização de responsabilidades das pessoas físicas que atuam no desenvolvimento da atividade, já que o risco inerente à atividade empresarial não pode conduzir à presunção de automática responsabilidade penal às pessoas que compõem órgãos de direção e àqueles que recebem, por delegação, os deveres de fiscalização.

A posição de garantidores dos empresários e membros dos órgãos de direção se encontra prevista na alínea $c$ do $\S 2$ ํㅡㅁ do artigo 13 do Código Penal, que emparelha a omissão à conduta comissiva quando há um dever de agir do sujeito para evitar um resultado cujo risco de ocorrência foi criado por seu comportamento anterior.

Não obstante, diante da complexidade da atividade empresarial, é habitual que nas grandes corporações exista uma fragmentação das funções 
desenvolvidas, o que não é diferente quando se trata da incumbência de vigilância e controle dos focos de perigos. O dever de garantia que inicialmente cabe àqueles que criam e gerenciam a atividade pode, então, ser delegado a outros agentes da organização, fazendo surgir novas posições de garantidores.

Concebendo-se um sistema de autorregulação, o criminal compliance configura importante medida de governança corporativa. Trata-se de uma estrutura com a finalidade precípua de prevenir a ocorrência de delitos. E o compliance officer, como profissional responsável por estabelecer, fazer cumprir, e fiscalizar o projeto, recebe por delegação os deveres de vigilância e controle da atividade no que tange à observância da legalidade, incumbindo-lhe contribuir para evitar crimes no exercício da atividade empresarial.

A adoção de um direito penal garantista impede a responsabilização automática dos profissionais que compõem os órgãos de direção empresarial e os que fazem parte dos setores de compliance. Há preocupação com a determinação e a delimitação dos pressupostos da responsabilidade penal dos indivíduos que ocupam referido cargo. A análise da punibilidade desses agentes não deve ser feita a partir de uma perspectiva meramente formal da posição de garantidor. Afinal, apesar da necessidade de adaptação dos institutos do direito penal clássico ao novo contexto criminal empresarial e da dificuldade em se delimitar a autoria nos crimes cometidos no âmbito de corporações complexas, a resposta a essa criminalidade não pode se dar sem a observância dos pressupostos estabelecidos pela teoria do crime.

Conclui-se que o compliance officer e os diretores das sociedades empresárias não responderão por todo e qualquer desvio que ocorra no âmbito da atividade empresarial. Apesar de assumirem ou possuírem a função de contenção dos riscos nas corporações, ou seja, ainda que sejam garantidores no âmbito empresarial, a responsabilidade penal por omissão imprópria exige a verificação de rigorosos pressupostos no caso concreto. A teoria do delito não se resume a uma enumeração de institutos pertencentes ao direito penal, trata-se de verdadeiro método a ser seguido para verificação da responsabilidade individual, o que confere cientificidade a esse ramo do direito e segurança jurídica. 


\section{Referências}

ABBI; FEBRABAN. Documento consultivo: função de compliance. 2004. Disponível em: <www.abbi.com.br/funcaodecompliance.html>. Acesso em: 10 fev. 2020.

BACIGALUPO, Enrique. Compliance y derecho penal. Cizur Menor: Arazandi, 2011.

BAJO FERNÁNDEZ, Miguel; BACIGALUPO, Silvina. Derecho penal económico. Madri: Ed. Centro de Estudios Ramón Areces S.A., 2001.

BRANDÃO, Cláudio. Teoria jurídica do crime. 5. ed. Belo Horizonte: D’Plácido, 2019.

ESTELITTA, Heloisa. Responsabilidade penal dos dirigentes de empresas por omissão: estudo sobre a responsabilidade omissiva imprópria de dirigentes de sociedades anônimas, limitadas e encarregados de cumprimento por crimes praticados por membros da empresa. São Paulo: Marcial Pons, 2017.

FEIJÓO SÁNCHEZ, Bernardo José. Autoria e participação em organizações empresariais complexas. Tradução de Vânia Costa Ramos. Revista Liberdades, São Paulo, n. 9, p. 26-57, jan./abr. 2012. Disponível em: <http://201.23.85.222/ biblioteca/index.asp?codigo_sophia=91297>. Acesso em: 23 fev. 2020.

KAUFMANN, Armin. Dogmática de los delitos de omisión. Tradução de Joaquín Cuello Contreras e José Luis Serrano González de Murillo. Madri: Marcial Pons, 2006.

LAFUENTE, Alfredo Liñán. La responsabilidad penal del compliance officer. Cizur Menor: Thomson Reuters Aranzadi, 2019.

LUZ, Ilana Martins. Compliance e omissão imprópria. Belo Horizonte: D’Plácido, 2019.

MARTÍN, Adán Nieto. Problemas fundamentales del cumplimiento normativo en el derecho penal. In: LOTHAR, Kuhlen; MONTIEL, Juan Pablo; GIMENO, Iñigo Ortiz de Urbina (Ed.). Compliance y teoría del derecho penal. Madri: Marcial Pons, 2013. 
MAYRINK, Renata Pereira. Responsabilidade penal do compliance officer: a omissão imprópria e os pressupostos para a tipicidade. Dissertação (mestrado em direito) - Pontifícia Universidade Católica de Minas Gerais, Belo Horizonte, 2020. Disponível em: <www.biblioteca.pucminas.br/teses/Direito_ RenataPereiraMayrink_8217.pdf>. Acesso em: 30 mar. 2020.

NIETO, Adán. Responsabilidad social, gobierno corporativo y autorregulación: sus influencias en el derecho penal de la empresa. Política Criminal, Santiago, v. 3, n. 5, p. 1-118, jul. 2008. Disponível em: <http:// politcrim.com/wp-content/uploads/2019/04/A_3_5.pdf>. Acesso em: 29 nov. 2019.

PALHARES, Cinthia Rodrigues Menescal. Aspectos político-criminais das sanções penais econômicas no direito brasileiro. In: SOUZA, Artur de Brito Gueiros (Org.). Inovações no direito penal econômico: contribuições criminológicas, político-criminais e dogmáticas. Brasília: Escola Superior do Ministério Público da União, 2011. seção II, p. 147-175.

PEREIRA, Henrique Viana. A função social da empresa e as repercussões sobre a responsabilidade civil e penal dos empresários. Tese (doutorado em direito) - Pontifícia Universidade Católica de Minas Gerais, Belo Horizonte, 2014. Disponível em: <www.biblioteca.pucminas.br/teses/Direito_PereiraHVd_1. pdf>. Acesso em: 21 fev. 2020.

PLANAS, Ricardo Robles. Estudos de dogmática jurídico-penal: fundamentos, teoria do delito e direito penal econômico. 2. ed. Belo Horizonte: D’Plácido, 2016.

REBOUÇAS, Sérgio Bruno Araújo. Omissão imprópria do empresário: o problema da delegação dos deveres de garantia nas estruturas empresariais complexas. Revista Brasileira de Ciências Criminais, São Paulo, v. 26, n. 143, p. 45-86, maio 2018. Disponível em: <http://201.23.85.222/biblioteca/index. asp?codigo_sophia=143403>. Acesso em: 23 out. 2019.

RODRIGUES, Anabela Miranda. Direito penal económico. Coimbra: Almedina, 2019.

SALLES, Leonardo Guimarães. Criminal compliance: a delimitação da responsabilidade penal nas organizações empresariais complexas. Dissertação (mestrado em direito) - Pontifícia Universidade Católica de Minas Gerais, Belo Horizonte, 2016. Disponível em: <www.biblioteca.pucminas.br/teses/ Direito_SallesLG_1.pdf>. Acesso em: 10 fev. 2020. 
SARCEDO, Leandro. Compliance e responsabilidade penal da pessoa jurídica: construção de um novo modelo de imputação, baseado na culpabilidade corporativa. Tese (doutorado em direito) - Faculdade de Direito, Universidade de São Paulo. São Paulo, 2014. Disponível em: <www.teses.usp.br/ teses/disponiveis/2/2136/tde-07122015-163555/pt-br.php>. Acesso em: 25 set. 2019.

SEBASTIÃO FILHO, Jorge. A criminalização de condutas de perigo abstrato e a tutela de bens jurídicos supraindividuais nos delitos econômicos. Revista Jurídica, s.1., v. 25, n. 9, p. 33-57, dez. 2010. Disponível em: <http://revista. unicuritiba.edu.br/index.php/RevJur/article/view/58>. Acesso em: 11 set. 2019.

SILVA SÁNCHEZ, Jesús-Maria. Deberes de vigilância y compliance empresarial. In: LOTHAR, Kuhlen; MONTIEL, Juan Pablo; GIMENO, Iñigo Ortiz de Urbina (Ed.). Compliance y teoría del derecho penal. Madri: Marcial Pons, 2013.

. Teoría del delito y derecho penal económico. Revista Brasileira de Ciências Criminais, São Paulo, v. 20, n. 99, p. 327-356, nov./dez. 2012. Disponível em: $<$ http://201.23.85.222/biblioteca/index.asp?codigo_sophia=98496>. Acesso em: 23 out. 2019.

SILVEIRA, Renato de Mello Jorge; DINIZ, Eduardo Saad. Compliance, direito penal e lei anticorrupção. São Paulo: Saraiva, 2015.

SOUZA, Artur de Brito Gueiros. Da criminologia à política-criminal: direito penal econômico e o novo direito penal. In: SOUZA, Artur de Brito Gueiros (Org.). Inovações no direito penal econômico: contribuições criminológicas, político-criminais e dogmáticas. Brasília: Escola Superior do Ministério Público da União, 2011. seção II, p. 105-145.

SOUZA, Washington Peluso Albino de. Primeiras linhas de direito econômico. Belo Horizonte: Rabelo \& Brasil Ltda, 1977.

TAVARES, Juarez. Fundamentos de teoria do delito. Florianópolis: Empório do Direito, 2018.

TIEDMANN, Klaus. El concepto de derecho económico, de derecho penal económico y de delito económico. Revista Chilena de Derecho, Santiago, v. 10, p. 59-68, 1983. Disponível em: <https://dialnet.unirioja.es/descarga/ articulo/2649428.pdf>. Acesso em: 25 set. 2019. 